\title{
Resisting temptation: Decreasing alcohol-related affect and drinking behavior by training response inhibition
}

Citation for published version (APA):

Houben, K., Nederkoorn, C., Wiers, R. W., \& Jansen, A. (2011). Resisting temptation: Decreasing alcoholrelated affect and drinking behavior by training response inhibition. Drug and Alcohol Dependence, 116(13), 132-136. https://doi.org/10.1016/j.drugalcdep.2010.12.011

Document status and date:

Published: 01/01/2011

DOI:

10.1016/j.drugalcdep.2010.12.011

Document Version:

Publisher's PDF, also known as Version of record

Document license:

Taverne

Please check the document version of this publication:

- A submitted manuscript is the version of the article upon submission and before peer-review. There can be important differences between the submitted version and the official published version of record.

People interested in the research are advised to contact the author for the final version of the publication, or visit the DOI to the publisher's website.

- The final author version and the galley proof are versions of the publication after peer review.

- The final published version features the final layout of the paper including the volume, issue and page numbers.

Link to publication

\footnotetext{
General rights rights.

- You may freely distribute the URL identifying the publication in the public portal. please follow below link for the End User Agreement:

www.umlib.nl/taverne-license

Take down policy

If you believe that this document breaches copyright please contact us at:

repository@maastrichtuniversity.nl

providing details and we will investigate your claim.
}

Copyright and moral rights for the publications made accessible in the public portal are retained by the authors and/or other copyright owners and it is a condition of accessing publications that users recognise and abide by the legal requirements associated with these

- Users may download and print one copy of any publication from the public portal for the purpose of private study or research.

- You may not further distribute the material or use it for any profit-making activity or commercial gain

If the publication is distributed under the terms of Article $25 f a$ of the Dutch Copyright Act, indicated by the "Taverne" license above, 


\title{
Resisting temptation: Decreasing alcohol-related affect and drinking behavior by training response inhibition
}

\author{
Katrijn Houben ${ }^{\mathrm{a}, *}$, Chantal Nederkoorn ${ }^{\mathrm{a}}$, Reinout W. Wiers ${ }^{\mathrm{b}}$, Anita Jansen ${ }^{\mathrm{a}}$ \\ a Clinical Psychological Science, Maastricht University, Maastricht, The Netherlands \\ ${ }^{\mathrm{b}}$ Department of Psychology, University of Amsterdam, Amsterdam, The Netherlands
}

\section{A R T I C L E I N F O}

\section{Article history:}

Received 16 September 2010

Received in revised form 6 December 2010

Accepted 7 December 2010

Available online 1 February 2011

\section{Keywords:}

Alcohol

Response inhibition

Go/no-go task

Implicit attitudes

\begin{abstract}
A B S T R A C T
According to dual-process models, excessive alcohol use emerges when response inhibition ability is insufficient to inhibit automatic impulses to drink alcohol. This study examined whether strengthening response inhibition for alcohol-related cues decreases alcohol intake. Fifty-two heavy drinking students were randomly assigned to one of two conditions: In the beer/no-go condition, participants performed a go/no-go task that consistently paired alcohol-related stimuli with a stopping response, to increase response inhibition for alcohol-related stimuli. In the beer/go condition, in contrast, participants were always required to respond to alcohol-related stimuli during the go/no-go task. Before and after the go/no-go manipulation, we measured weekly alcohol intake and implicit attitudes toward alcohol. In addition, we measured alcohol consumption during a taste test immediately after the go/no-go manipulation. Following the manipulation, participants in the beer/no-go condition demonstrated significantly increased negative implicit attitudes toward alcohol, and a significant reduction in weekly alcohol intake, while participants in the beer/go condition showed a non-significant increase in implicit positive attitudes toward alcohol and a significant increase in weekly alcohol intake. This study demonstrates that repeatedly stopping prepotent responses toward alcohol-related stimuli can be an effective strategy to reduce excessive alcohol use.
\end{abstract}

(C) 2011 Elsevier Ireland Ltd. All rights reserved.

\section{Introduction}

Contemporary dual-process theories propose that drinking behavior is guided by two distinct cognitive systems: One system is associative and operates through fast automatic processes, while the other system is propositional and operates through slower controlled processes (Bechara et al., 2006; Deutsch and Strack, 2006; Wiers et al., 2007). According to these theories, drinking behavior is instigated by automatic processes, which generate an automatic impulse to drink alcohol, unless one is able to engage in effortful controlled processing to regulate automatic impulses. In line with these models, stronger automatic associations between alcohol and positive affect predict increased levels of alcohol consumption (Houben and Wiers, 2007a,b; Houben and Wiers, 2008; Jajodia and Earleywine, 2003; McCarthy and Thompsen, 2006), especially when cognitive control abilities, such as response inhibition and working memory, are low (Houben and Wiers, 2009; Thush et al., 2008).

\footnotetext{
* Corresponding author at: Clinical Psychological Science, Maastricht University, PO BOX 616, 6200 MD Maastricht, The Netherlands. Tel.: +31 433881953.

E-mail addresses: K.Houben@maastrichtuniversity.nl, k.houben@psychology.unimaas.nl (K. Houben).
}

The clinical implication of these insights is that interventions might benefit from procedures that decrease automatic processes which lead to excessive alcohol use. Recent research indeed suggests that automatic alcohol-related affective processes are amenable to change and that decreasing these automatic impulses reduces alcohol intake (Houben et al., 2010). Alternatively, interventions might also aim to strengthen cognitive control abilities such as response inhibition and working memory, which are important moderators of the predictive relationship between automatic impulses and drinking behavior. If cognitive control can be enhanced, automatic impulses could be regulated more easily and control over drinking behavior could be increased. Consistent with this perspective, Jones et al. (2011) demonstrated decreased alcohol intake following a manipulation that primed inhibitory control compared to a manipulation that primed impulsive behavior. Hence, these findings indicate that increasing inhibitory control may indeed be a valuable technique to decrease alcohol use. However, Jones et al. (2011) did not include a control condition or pretest measures in their study, which makes it impossible to determine whether both the impulsivity and the inhibition manipulation effectively influenced alcohol consumption relative to baseline. Moreover, Jones et al. (2011) merely induced a temporary state of impulsivity or inhibition. While priming such a mental state is interesting to show causality, it is highly unlikely that temporar- 
ily priming an inhibitory mental state induces long-term effects on both inhibitory control and drinking behavior.

The current study further explores this issue by examining whether increasing or decreasing inhibitory control respectively decreases or increases alcohol consumption relative to baseline. Moreover, the present study tested a behavioral training of inhibition that consistently paired certain stimuli with a stopping response in an adapted version of a go/no-go task. Recent research confirms that response inhibition can be trained by consistently mapping stimuli onto a stopping response (no-go) as this effectively strengthens the ability to inhibit responses to those stimuli (Verbruggen and Logan, 2008). Moreover, the effect of such a behavioral training should be even more potent when rewarding stimuli, such as alcohol cues, are mapped onto a stopping response. Because positive stimuli automatically elicit approach tendencies due to their reward value, pairing such stimuli with situational cues signaling that approach is unwanted (no-go signal) should result in response conflict (Veling and Aarts, in press; Veling et al., 2008). As a result, pairing such rewarding stimuli with stopping responses causes a devaluation of those stimuli (Veling et al., 2008) and increases motor inhibition for those stimuli (Veling and Aarts, in press) in an effort to resolve the response conflict. Importantly, the consistent mapping of stimuli onto stopping is not limited to shortterm effects on behavior and may even cause automatic inhibition to develop (Verbruggen and Logan, 2008).

Hence, recent research shows that training response inhibition changes both evaluations of stimuli that were associated with a stopping response, and increases inhibitory control over these stimuli. In this study, we used a similar go/no-go task that consistently paired alcohol-related cues with a stopping response to strengthen the ability to inhibit responses to alcohol-related stimuli in heavy drinking college students. Especially for heavy drinkers, alcohol-related stimuli automatically elicit positive affect (Houben and Wiers, 2007a,b, 2008; Jajodia and Earleywine, 2003; McCarthy and Thompsen, 2006), and approach tendencies (Field et al., 2008; Palfai and Ostafin, 2003; Wiers et al., 2009). Therefore, it was expected that repeatedly pairing alcohol-related stimuli with a stopping response would decrease automatic affect that is elicited by alcohol-related stimuli as well as decrease alcohol intake.

\section{Methods}

\subsection{Participants}

Participants were 52 heavy drinking students of Maastricht University (33 female students; mean age $=22.37, \mathrm{SD}=4.92$ ), who regularly consumed beer. Participants were recruited via advertisements and flyers. The advertisements stated that participants were needed for research on attitudes and preferences for beer. Participants were screened for alcohol use and were only included if they consumed an average of 12 (males) or 10 (females) alcoholic consumptions or more per week and if beer was their preferred alcoholic beverage. On average, participants consumed 18.77 ( $\mathrm{SD}=8.30$; range $12-44$ ) Dutch standard drinking units of $10 \mathrm{~g}$ of alcohol per week over an average of 4.35 ( $\mathrm{SD}=1.57)$ drinking occasions, as measured with the timeline follow-back questionnaire (TLFB; Sobell and Sobell, 1990). On the alcohol use disorder identification test (AUDIT; Saunders et al., 1993), participants had an average score of $11.77(\mathrm{SD}=3.46)$ with $90 \%$ of the participants scoring above 8 , indicating hazardous drinking (Saunders et al., 1993).

\subsection{Materials and measures}

2.2.1. Go/no-go task. During the go/no-go task, four pictures of glasses of beer and four pictures of glasses of water were presented. Participants were instructed to press the space bar when a go cue was displayed on these pictures, and to refrain from responding when a no-go cue was shown. The go/no-go cues were the letters ' $\mathrm{p}$ ' and ' $\mathrm{f}$ ' (with counterbalanced instructions), displayed randomly in one of four corners of the pictures. In the beer/no-go condition, beer-related pictures were consistently paired with the no-go cue, while water pictures were consistently paired with the go cue. In the beer/go condition, beer-related pictures were always paired with the go cue, and water-related pictures were always paired with the no-go cue. The go/no-go task consisted of 80 trials, which were presented randomly but go or no-go trials were never presented more than four consecutive times, and each picture was presented once every eight trials. During each trial, picture and cue were presented together $(1500 \mathrm{~ms})$, followed by a question mark $(1000 \mathrm{~ms})$ at which time participants were allowed to respond. A green circle was displayed after a correct (non)response $(500 \mathrm{~ms})$, and a red cross an after incorrect (non)response $(500 \mathrm{~ms})$.

2.2.2. Implicit association test. Automatic affective associations with beer were measured with the implicit association test (IAT; Greenwald et al., 1998). The IAT is a computerized classification task during which participants have to classify stimuli into two target categories (e.g., alcohol and soft drinks) and two affective attribute categories (e.g., positive and negative), using a left and a right response key. The target and attribute categories are assigned to the response keys in two different combinations. The difference in reaction time between these two combination tasks reflects the association strength between the target categories and the attribute categories since it should be easier to combine associated concepts than to combine concepts that are not associated (Greenwald et al., 1998). In this study, the target categories were 'beer' (eight beer-related pictures) and 'water' (eight waterrelated pictures). The attribute categories were 'pleasant' (happy, jolly, energetic, funny, sociable, attractive, cheerful, smart) and 'unpleasant' (dull, miserable, sick, depressed, unhappy, disgusting, angry, foolish).

The IAT consisted of seven blocks. In the first and second block, participants respectively practiced classifying target stimuli as 'beer' or 'water' and attribute stimuli into the categories 'pleasant' and 'unpleasant' using a left and a right response key. In each block all stimuli of the respective categories were presented twice so that both blocks consisted of 32 trials. In the third (practice) and fourth block (test), participants had to classify stimuli belonging to one target category and one attribute category (e.g., beer and pleasant) with one response key and stimuli belonging to the other target category or the other attribute category (e.g., water and unpleasant) with the other response key. In the third block all stimuli were presented once for a total of 32 trials, while the fourth block consisted of 64 trials during which all stimuli were presented twice. During the fifth block, participants practiced the reversed response assignment of the target categories (i.e., if beer was previously sorted using the left response key, it now had to be sorted using the right response key). All target stimuli were presented four times for a total of 64 trials. In the sixth (practice) and seventh block (test), participants performed the reversed combination of targets and attributes (e.g., beer and unpleasant vs. water and pleasant). The sixth block presented all stimuli once for a total of 32 trials whereas the seventh block presented all stimuli two times and consisted of 64 trials.

The assignment of the attribute categories to the left and right response keys was counterbalanced across participants. Furthermore, the order of the combined sorting conditions (blocks 3, 4 and blocks 6,7 ) was also counterbalanced across participants so that half of the participants categorized beer with pleasant first and the other half categorized beer with unpleasant first. Stimuli appeared in the middle of the computer screen and the labels of the categories were presented in the upper corners of the computer screen consistent with the response assignment of the categories. Stimuli remained on screen until a correct response was given. The intertrial interval was $250 \mathrm{~ms}$. Categorization errors were signaled with a red " $\mathrm{X}$ " beneath the stimulus item.

2.2.3. Alcohol use. Alcohol use was measured with a modified version (Wiers et al., 1997) of the TLFB questionnaire (Sobell and Sobell, 1990). Participants were asked to indicate how many alcoholic beverages they consumed during each day of the past week. In addition, participants were also asked to report how many alcoholic beverages they normally drink on each day of a typical week to estimate average weekly alcohol use.

2.2.4. Taste test. Participants rated their thirst on a $100 \mathrm{~mm}$ visual analogue scale (VAS), and then they were presented one glass filled with $330 \mathrm{ml}$ of chilled beer. Participants were instructed to consume as much or as little as they wished in order to judge the beer on different aspects on four $100 \mathrm{~mm}$ VAS (unpleasant-pleasant; tasteless-strong tasting; bitter-sweet; flat-gassy). The experimenter left the test room during the taste test and returned after $10 \mathrm{~min}$. The experimenter then removed the glass of beer and the amount of beer consumed was measured outside the test room.

2.2.5. Demand. We probed participants for awareness of the purpose of the critical go/no-go manipulation with open questions asking participants to report what they thought was the goal of the study and what they considered to be the goal of the go/no-go task.

\subsection{Procedure}

After giving consent, participants first filled out the AUDIT. Next, participants performed the IAT and filled out the TLFB for the week prior to the study. Participants were then randomly divided into the beer/no-go condition ( $n=25 ; 8$ males) and the beer/go condition ( $n=27 ; 11$ males) and performed the go/no-go task (randomization was achieved by a tossing a coin, allocating participants randomly with equal probability to the two conditions). Afterwards, participants performed the IAT again (the same version as performed at pretest), participated in the taste test, and took home a shortened version (i.e., not including average use for each day) of the 
Table 1

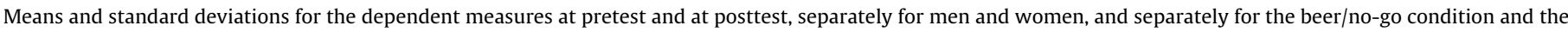
beer/go condition.

\begin{tabular}{|c|c|c|c|c|c|c|c|}
\hline \multirow[t]{2}{*}{ Time } & & \multicolumn{2}{|l|}{ IAT } & \multicolumn{2}{|c|}{ Weekly alcohol use } & \multicolumn{2}{|c|}{ Taste test } \\
\hline & & $M$ & SD & $M$ & SD & $M$ & SD \\
\hline \multirow[t]{4}{*}{ Pretest } & Men & .10 & .47 & 24.95 & 14.26 & & \\
\hline & Women & -.24 & .30 & 18.27 & 9.34 & & \\
\hline & Beer/go condition & -.12 & .45 & 18.70 & 10.06 & & \\
\hline & Beer/no-go condition & -.12 & .36 & 22.88 & 13.13 & & \\
\hline \multirow[t]{4}{*}{ Posttest } & Men & .06 & .44 & 27.47 & 18.41 & 264.67 & 81.07 \\
\hline & Women & -.21 & .33 & 18.33 & 10.89 & 152.23 & 75.56 \\
\hline & Beer/go condition & -.01 & .45 & 24.15 & 17.12 & 217.05 & 101.48 \\
\hline & Beer/no-go condition & -.21 & .30 & 19.22 & 11.44 & 167.75 & 103.43 \\
\hline
\end{tabular}

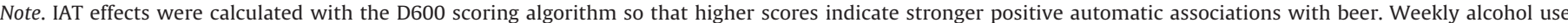

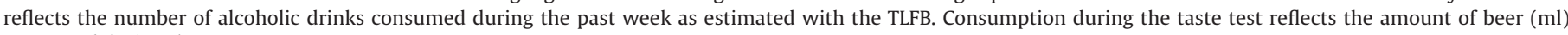
consumed during the taste test.

TLFB, which they had to fill in on a daily basis during the following week. One week later, participants returned this TLFB, were probed for awareness, and received 12.5 euro or 1.5 course credits as remuneration.

\section{Results}

None of the participants guessed the goal of the study or the purpose of the go/no-go manipulation. At baseline, there was no significant difference between conditions in age $(F=2.80)$ or AUDIT scores $(F<1)$. With respect to the go/no-go manipulation, results showed relatively low error percentages on both beer and water trials, in the beer/go condition $(M=.07, \mathrm{SD}=.19$, and $M=.01, \mathrm{SD}=.02$, respectively) and in the beer/no-go condition $(M=.01, \mathrm{SD}=.02$, and $M=.03, \mathrm{SD}=.03$, respectively).

\subsection{Implicit associations}

Mean IAT effects were calculated with the D600 algorithm (Greenwald et al., 2003), so that higher scores indicate stronger positive automatic associations with beer. At pretest, there was no difference between the two conditions on IAT scores $(F<1)$. There was, however, a significant effect of gender, $F(1,50)=9.78, p=.003$, $\eta_{\mathrm{p}}^{2}=.16$, indicating stronger positive associations with beer in men compared to women. The effect of the go/no-go manipulation on automatic associations was examined using a 2 (time: pretest or posttest) by 2 (condition: beer/no-go or beer/go) mixed Analysis of Covariance (ANCOVA) on IAT effects with repeated measures on the first factor. Since there was a significant difference in IAT scores between men and women at pretest, gender was added as a covariate to the model.

Results showed a significant effect of gender, $F(1,49)=9.53$, $p=.003, \eta_{\mathrm{p}}^{2}=.16$, demonstrating stronger positive associations with beer in men compared to women (see Table 1 ). The effects of condition and time did not reach significance $(F<1)$. Importantly, the expected time by condition interaction was significant, $F(1,49)=4.91, p=.03, \eta_{\mathrm{p}}^{2}=.09$, while the interaction of time and gender was not significant $(F<1)$. Follow-up analyses demonstrated a significant effect of both gender, $F(1,23)=6.08, p=.02$, $\eta_{\mathrm{p}}^{2}=.21$, and time, $F(1,23)=4.23, p=.05, \eta_{\mathrm{p}}^{2}=.16$, in the beer $/$ no-go condition, in the absence of a significant time by gender interaction $(F<2)$. Hence, repeatedly pairing beer-related pictures with a no-go cue significantly decreased positive associations with beer (see Fig. 1). In the beer/go condition, results showed only an effect of gender, $F(1,25)=4.07, p=.05, \eta_{\mathrm{p}}^{2}=.14$, while none of the other effects reached significance $(F<1)$. Thus, although the beer/go condition showed an increase in positive associations with beer (see Fig. 1), this trend was not significant.

\subsection{Taste test}

Differences between the two conditions in actual alcohol consumption during the taste test were analyzed using ANCOVA
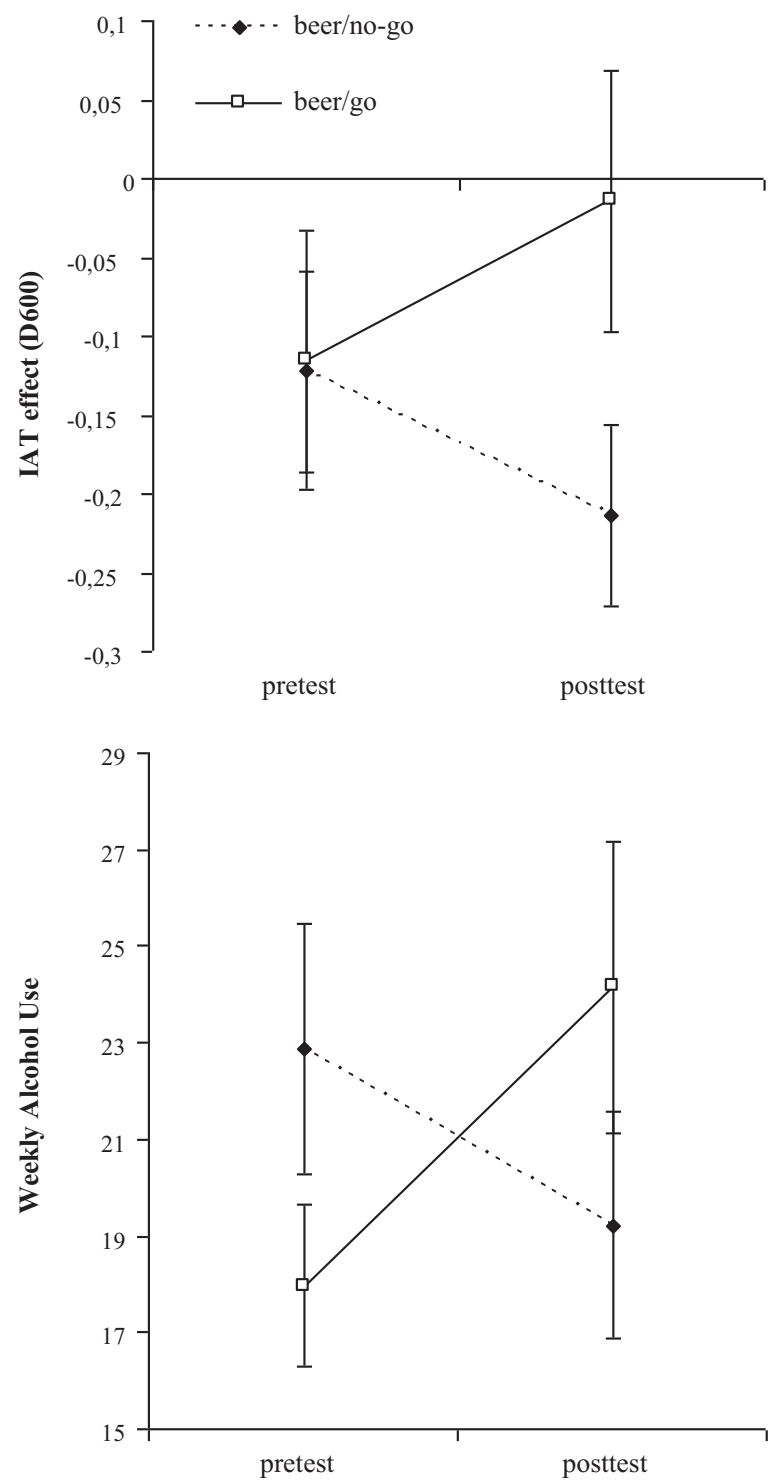

Fig. 1. Estimated marginal means for the D600 IAT score and for weekly alcohol use at pretest and posttest, separately for the beer/no-go condition and the beer/go condition. 
with condition as between-subjects factor, and both gender and thirst as covariates. The effect of condition was not significant, $F(1,48)=3.09, p=.09, \eta_{\mathrm{p}}^{2}=.06$, but showed a statistical trend in the expected direction with lower beer consumption in the beer/nogo condition $(\mathrm{EMM}=214.56, \mathrm{SE}=17.22)$ compared to the beer/go condition $(E M M=170.44, S E=17.91)$. Further, while the effect of thirst was not significant $(F<1)$, the effect of gender was significant, $F(1,48)=18.18, p<.001, \eta_{\mathrm{p}}^{2}=.28$, showing that men consumed significantly more beer compared to women (see Table 1 ).

\subsection{Weekly alcohol use}

For weekly alcohol use, there was an effect of gender at pretest, $F(1,50)=4.16, p=.05, \eta_{\mathrm{p}}^{2}=.08$, indicating that men consumed more alcohol during the week before the study than women. There was no significant difference between conditions in weekly alcohol use at pretest $(F<2)$. To test the effect of the go/no-go manipulation, we analyzed differences in weekly alcohol intake using a 2 (time: pretest or posttest) by 2 (condition: beer/no-go or beer/go) mixed ANCOVA with repeated measures on the first factor. To control for gender differences in alcohol consumption at pretest, gender was added as a covariate to the model. One participant in the beer/go condition failed to return the second TLFB. Therefore, these analyses were performed with 51 participants.

Results demonstrated a significant effect of gender, $F(1,48)=6.98, p=.01, \eta_{\mathrm{p}}^{2}=.13$, showing that men consumed significantly more alcohol than women (see Table 1). While neither the main effects of time and condition, nor the interaction of time and gender were significant $(F<1)$, the expected interaction between time and condition was significant, $F(1,48)=7.20$, $p=.01, \eta_{\mathrm{p}}^{2}=.13$. Follow-up analyses showed a significant effect of time in the beer/no-go condition, $F(1,23)=5.05, p=.04, \eta_{\mathrm{p}}^{2}=.18$, indicating a significant decrease in alcohol intake following the manipulation compared to alcohol intake at pretest (see Fig. 1). None of the effects involving gender reached significance $(F<2.5)$. In the beer/go condition, in addition to the significant effect of gender, $F(1,24)=9.74, p=.01, \eta_{\mathrm{p}}^{2}=.29$, the effect of time was also significant, $F(1,24)=5.93, p=.02, \eta_{\mathrm{p}}^{2}=.20$, demonstrating a significant increase in alcohol intake during the week following the manipulation relative to pretest alcohol intake (see Fig. 1). The interaction of gender and time was not significant $(F<2)$.

\section{Discussion}

In this study, we examined whether training response inhibition by consistently pairing alcohol-related stimuli with a stopping response would decrease alcohol intake. Further, it was tested whether this pairing of alcohol with a stopping response would decrease the positive affect that is automatically associated with alcohol-related stimuli. As expected, participants who repeatedly inhibited responding to alcohol cues showed both increased negative automatic associations with alcohol-related stimuli and reduced alcohol intake following the manipulation. In contrast, the consistent pairing of alcohol-related stimuli with a go response did not significantly change automatic associations with alcoholrelated stimuli, but did result in an increase in alcohol consumption.

These findings are in line with the results by Veling et al. (2008) who demonstrated that the repeated pairing of no-go cues with positive stimuli leads to a devaluation of these stimuli. Moreover, whereas Veling et al. (2008) demonstrated that their manipulation decreased self-reported ratings of individual stimuli that were paired with a stopping response, we were able to demonstrate a devaluation of the category beer on an automatic level. Importantly, these findings show that positive affect that is automatically assigned to alcohol-related stimuli can effectively be decreased by consistently stopping a response to alcohol-related cues. One explanation for this finding is that stopping responses to stimuli that elicit approach tendencies creates a response conflict that is resolved by devaluating the stimuli (cf. Veling et al., 2008). Alternatively, it is also possible that stopping a response to stimuli directly leads to decreased affective associations of those stimuli, regardless of whether this creates a response conflict and future research will need to examine this issue further.

Importantly, for the first time, we demonstrated an effect of the go/no-go manipulation on actual behavior. Specifically, participants who consistently had to stop a response to alcohol-related stimuli consumed significantly less alcohol in the week following the manipulation compared to their weekly alcohol intake before the manipulation. The repeated pairing of alcohol-related stimuli with a go response, however, led to a significant increase in weekly alcohol consumption. There was also a non-significant trend for consumption during the taste test, with participants in first condition drinking somewhat less beer compared to participants in the latter condition. Hence, the present findings suggest that pairing alcohol cues with a go response increased impulsivity and thereby increased drinking, while pairing alcohol cues with a no-go response increased inhibitory control over alcoholrelated responses and drinking behavior. However, it should be noted that we only found a significant effect of the manipulation on self-reported drinking and a non-significant trend on actual consumption during a taste test. Therefore, these findings need to be replicated in future studies using different outcome measures of drinking behavior to further examine the value of this manipulation for reducing alcohol use.

Further, the present study did not include a dependent measure of response inhibition, and therefore the present findings cannot inform us whether the go/no-go manipulation indeed strengthened response inhibition for alcohol-related stimuli. The reason for not including such a dependent measure of response inhibition is that performing such a task after the manipulation might decrease or even erase the effects of the manipulation on behavior (cf. Wiers et al., 2010). Therefore, the present study focused on the effects of the manipulation on drinking behavior to first test whether this training procedure has any merit for changing drinking behavior. Importantly, previous research using similar go/no-go manipulations also showed that this manipulation indeed strengthens response inhibition for those stimuli that are consistently paired with a stopping response (Verbruggen and Logan, 2008). Hence, based on these findings it is likely that a similar change in inhibitory processes also caused the observed change in alcohol use in the present study, although future research will have to examine this issue further before any solid conclusions can be reached.

Further, the present findings showed evidence for an effect of the go/no-go manipulation on drinking behavior up to a week following the manipulation. However, it is unclear how long these effects persisted. Similarly, previous studies using similar training procedures also did not include a long-term follow-up of training effects (Verbruggen and Logan, 2008; Veling et al., 2008). Consequently, the duration of the improvements from the response inhibition training remains unclear at this time. This issue also needs to be addressed in future research by examining the effect of the training on alcohol consumption over a longer period, and by comparing the duration of effects of more extensive training procedures.

To conclude, this study provides initial data demonstrating the utility of a novel, conceptually derived intervention for reducing alcohol abuse by strengthening inhibitory control over drinking behavior. The implication of these findings is that procedures that aim to strengthen response inhibition may prove to be a useful supplement to existing interventions, especially since alcohol 
abuse is associated with deterioration of inhibitory control abilities (Goldstein and Volkow, 2002; Noël et al., 2007). However, the present sample did consist solely of hazardous college drinkers and therefore it is unclear whether the present findings also generalize to clinical samples. We hope that these initial findings will stimulate future research that aims to extend and replicate these findings in clinical samples to further investigate the potential clinical significance of response inhibition training for reducing alcohol abuse.

\section{Role of funding source}

Funding for this study was provided by a grant from ERAB: The European Foundation for Alcohol Research awarded to the first author and a grant from the Technology Foundation STW to the third author; the sponsors had no further role in study design; in the collection, analysis and interpretation of data; in the writing of the report; or in the decision to submit the paper for publication.

\section{Contributors}

Katrijn Houben designed the study, performed the statistical analysis, and wrote the first draft of the manuscript. All authors contributed to and have approved the final manuscript.

\section{Conflict of interest}

All other authors declare that they have no conflicts of interest.

\section{References}

Bechara, A., Noel, X., Crone, E.A., 2006. Loss of willpower: abnormal neural mechanisms of impulse control and decision making in addiction. In: Wiers, R.W., Stacy, A.W. (Eds.), Handbook of Implicit Cognition and Addiction. SAGE Publishers, Thousand Oaks, pp. 215-232.

Deutsch, R., Strack, F., 2006. Reflective and impulsive determinants of addictive behavior. In: Wiers, R.W., Stacy, A.W. (Eds.), Handbook of Implicit Cognition and Addiction. SAGE Publishers, Thousand Oaks, pp. 45-57.

Field, M., Kiernan, A., Eastwood, B., Child, R., 2008. Rapid approach responses to alcohol cues in heavy drinkers. J. Behav. Ther. Exp. Psychiatry 39, 209218.

Goldstein, R.Z., Volkow, N.D., 2002. Drug addiction and its underlying neurobiological basis: neuroimaging evidence for the involvement of the frontal cortex. Am. J. Psychiatry 159, 1642-1652.

Greenwald, A.G., McGhee, D.E., Schwartz, J.L.K., 1998. Measuring individual differences in implicit cognition: the implicit association test. J. Pers. Soc. Psychol. 74, 1464-1480.

Greenwald, A.G., Nosek, B.A., Banaji, M.R., 2003. Understanding and using the implicit association test: I. An improved scoring algorithm. J. Pers. Soc. Psychol. $85,197-216$.
Houben, K., Havermans, R.C., Wiers, R.W., 2010. Learning to dislike alcohol: conditioning negative implicit attitudes towards alcohol and its effects on drinking behavior. Psychopharmacology 211, 79-86.

Houben, K., Wiers, R.W., 2007a. Are drinkers implicitly positive about drinking alcohol? Personalizing the alcohol-IAT to reduce negative extrapersonal contamination. Alcohol Alcohol. 42, 301-307.

Houben, K., Wiers, R.W., 2007b. Personalizing the alcohol-IAT with individualized stimuli: relationship with drinking behavior and drinking-related problems. Addict. Behav. 32, 2852-2864.

Houben, K., Wiers, R.W., 2008. Implicitly positive about alcohol? Implicit positive associations predict drinking behavior. Addict. Behav. 33, 979-986.

Houben, K., Wiers, R.W., 2009. Response inhibition moderates the influence of implicit associations on drinking behavior. Alcohol. Clin. Exp. Res. 33, 626-633.

Jajodia, A., Earleywine, M., 2003. Measuring alcohol expectancies with the implicit association test. Psychol. Addict. Behav. 17, 126-133.

Jones, A., Guerrieri, R., Fernie, G., Cole, J., Goudie, A., Field, M., 2011. The effects of priming restrained versus disinhibited behaviour on alcohol-seeking in social drinkers. Drug Alcohol Depend. 113, 55-61.

McCarthy, D.M., Thompsen, D.M., 2006. Implicit and explicit measures of alcohol and smoking cognitions. Psychol. Addict. Behav. 20, 436-444.

Noël, X., Bechara, A., Dan, B., Hanak, C., Verbanck, P., 2007. Response inhibition deficit is involved in poor decision making under risk in nonamnesic individuals with alcoholism. Neuropsychology 21, 778-786.

Palfai, T.P., Ostafin, B.D., 2003. Alcohol-related motivational tendencies in hazardous drinkers: assessing implicit response tendencies using the modified-IAT. Behav. Res. Ther. 41, 1149-1162.

Saunders, J.B., Aasland, O.G., Babor, T.F., De la Fuente, J.R., Grant, M., 1993. Development of the alcohol use disorders identification test (AUDIT): WHO collaborative project on early detection of persons with harmful alcohol consumption. Addiction 88, 791-804.

Sobell, L.C., Sobell, M.B., 1990. Self-report issues in alcohol abuse: state of the art and future directions. Behav. Assess. 12, 77-90.

Thush, C., Wiers, R.W., Ames, S.L., Grenard, J.L., Sussman, S., Stacy, A.W., 2008. Interactions between implicit and explicit cognition and working memory capacity in the prediction of alcohol use in at-risk adolescents. Drug Alcohol Depend. 94 116-124.

Veling, H., Aarts, H. Unintentional preparation of motor impulses after incidental perception of need-rewarding objects. Cogn. Emot., in press.

Veling, H., Holland, R.W., van Knippenberg, A., 2008. When approach motivation and behavioral inhibition collide: behavior regulation through stimulus devaluation. J. Exp. Soc. Psychol. 44, 1013-1019.

Verbruggen, F., Logan, G.D., 2008. Automatic and controlled response inhibition: associative learning in the Go/No-Go and Stop-Signal paradigms. J. Exp. Psychol Gen. 137, 649-672.

Wiers, R.W., Rinck, M., Dictus, M., van den Wildenberg, E., 2009. Relatively strong automatic appetitive action-tendencies in male carriers of the OPRM1 G-allele. Genes Brain Behav. 8, 101-106.

Wiers, R.W., Hoogeveen, K.-J., Sergeant, J.A., Gunning, W.B., 1997. High- and low-dose alcohol-related expectancies and the differential associations with drinking in male and female adolescents and young adults. Addiction 92 $871-888$

Wiers, R.W., Bartholow, B.D., van den Wildenberg, E., Thush, C., Engels, R.C.M.E. Sher, K.J., Grenard, J.L., Ames, S.L., Stacy, A.W., 2007. Automatic and controlled processes and the development of addictive behaviors in adolescents: a review and a model. Pharmacol. Biochem. Behav. 86, 263-283.

Wiers, R.W., Rinck, M., Kordts, R., Houben, K., Strack, F., 2010. Retraining automatic action-tendencies to approach alcohol in hazardous drinkers. Addiction 105, $279-287$. 